\title{
Fatty acids, lipid peroxidation and diseases
}

\author{
BY MICHEL E. BÉGIN \\ Department of Biology, Faculty of Sciences, University of Sherbrooke, Sherbrooke, Quebec \\ $J I K 2 R I$, Canada
}

Many studies have implicated oxygen radicals and lipid peroxidation in various diseases. Polyunsaturated fatty acids (PUFA) are believed to be one of the keys for understanding the damage that can be done to cells by free radicals. Free radical attack on PUFA may result in (1) the loss of PUFA which play important roles in cell membrane structure and as precursors for eicosanoid (prostaglandin and leukotriene) formation and (2) the formation of lipid peroxides and related compounds which can themselves cause damage to other cellular constituents.

It is feared that provision of PUFA, which would provide further substrates for free radical attack, might make diseases worse. Contrary to this idea, evidence from recent studies on the effect of PUFA supplementation on a variety of diseases supports the view that PUFA have desirable rather than undesirable effects. Examples of desirable effects of PUFA supplementation on rheumatoid arthritis and other inflammatory disorders, alcoholic liver damage, radiation protection, and especially cancer is presented.

\section{ANTI-TUMOUR EFFECTS OF PUFA}

Cancer cells, as compared to normal cells, are resistant to lipid peroxidation (Masotti et al. 1989; Horrobin \& Bégin, 1989). This difference in lipid peroxidation is thought to be due to (1) a low PUFA content in tumours compared to normal cells, (2) a decreased concentration in tumours of cytochrome P-450 which normally participates in the initiation of lipid peroxidation, (3) a decreased content of NADPH in tumours and (4) an elevated antioxidative activity in tumours. These factors are present singly or in combination in cancer cells. Of all these factors, the critical one appears to be the antioxidants:PUFA ratio which is increased many times in tumour cells compared with normal cells (Cheeseman et al. 1984, 1986; Masotti et al. 1988). Also there is evidence that the degree of tumourigenicity correlates inversely with PUFA content (Roos \& Choppin, 1984, 1985). For these reasons, supplementation of specific PUFA may be desirable in controlling tumour development. Therefore, we examined the effects of various PUFA added exogenously at concentrations that are cytotoxic to carcinoma cells but not to normal cells (Bégin et al. 1986).

The relative cell killing potential of PUFA containing two (linoleate, LA), three $(\alpha$-linolenate, ALA; $\gamma$-linolenate, GLA; dihomo- $\gamma$-linolenate, DGLA), four (arachidonate, AA), five (eicosapentaenoate, EPA) and six (docosahexaenoate, DHA) double bonds were determined following direct exposure on growing tumour and non-tumour cells in vitro. Initial experiments revealed that a dose of $10-30 \mu \mathrm{g} / \mathrm{ml}(0.5-1.5 \mathrm{ng} / \mathrm{cell})$ of PUFA was lethal to tumour cells but not to non-tumour cells. The lethal effect was slow, taking 3-4 d to become apparent and 7-10 d to become complete. As shown in Fig. 1, tumour cells were more sensitive to cytotoxic PUFA than non-tumour cells, and different PUFA showed different cytotoxic potential. GLA and AA were the most effective 

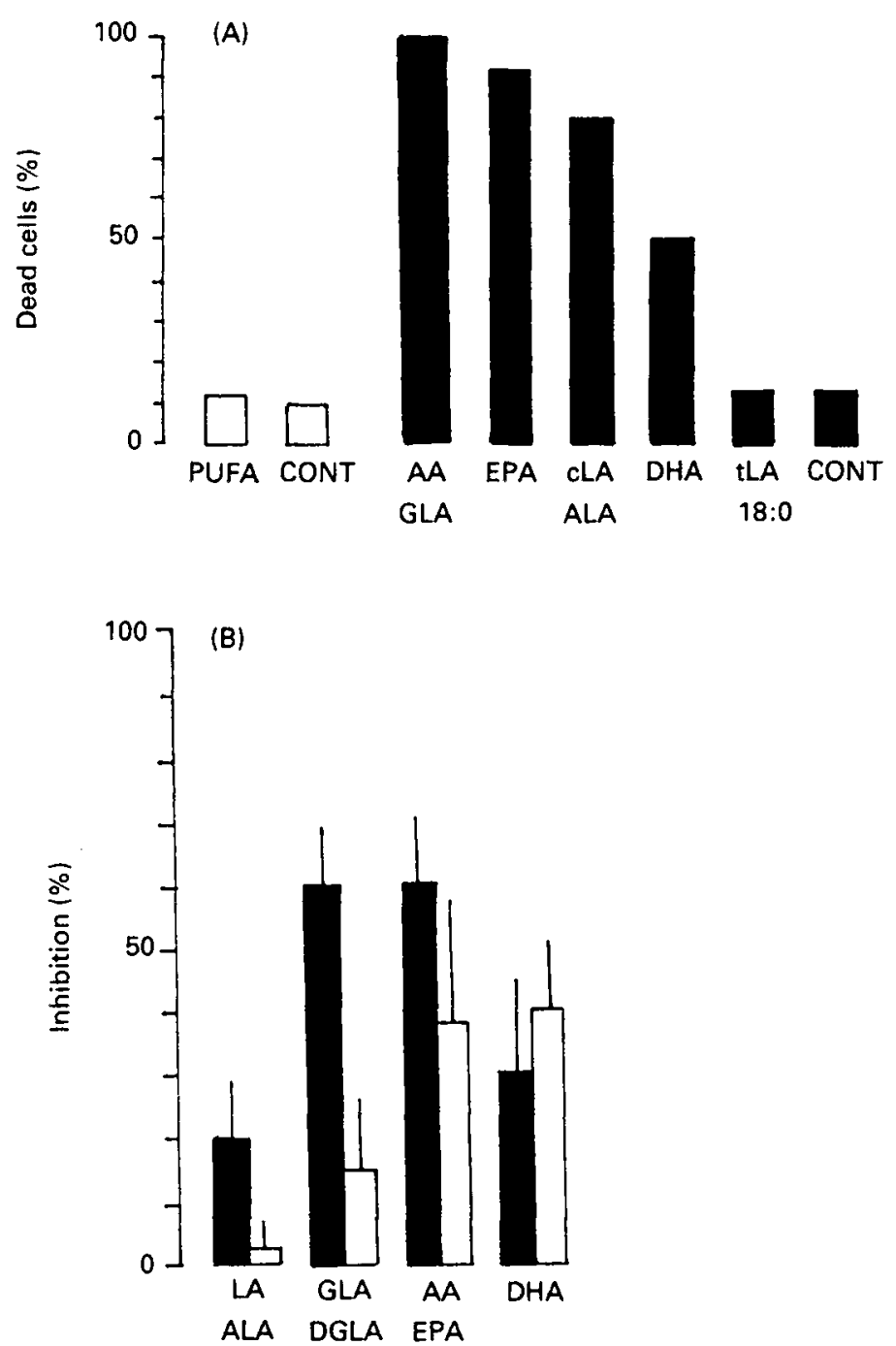

Fig. 1. Relative toxic effects of $n-3$ and $n-6$ polyunsaturated fatty acids (PUFA) on tumour and non-tumour cells. Tumour (human breast, ZR-75-1; human lung, A-549; human prostate, PC-3; 1 ) and non-tumour (human skin fibroblast, CCD-41SK; simian kidney, CV-1 and BSC-1; canine kidney, MDCK; $\square$ ) cell lines were seeded at $1 \times 10^{4}$ cells per well in twenty-four-well tissue culture plates and challenged with $20 \mu \mathrm{g}$ fatty acid/ml 1 $\mathrm{d}$ after seeding. Cell viability was determined 9-14 $\mathrm{d}$ after supplementation by the trypan-blue-dye exclusion method. Because their response was similar for each fatty acid, the different tumour cell lines were grouped together. The same applies in the case of the different non-tumour cell lines. Relative cytotoxic potential was determined on human breast tumour cells. (A), PUFA-induced lethal effects. Pcrcentage of dead cells was evaluated as: (number of dead cells in a culture/total number of cells) $\times 100$; (B), ability of PUFA to inhibit the growth of tumour and non-tumour cells. Percentage inhibition of cell production was calculated as: ((total number of cells in supplemented cultures/total number of cells in unsupplemented cultures) $\times 100$ ) $-100 \%$. AA, arachidonate; EPA, eicosapentaenoate; cLA, cis-linoleate; DHA, docosahexaenoate; GLA, $\gamma$-linolenate; ALA, $\alpha$-linolenate; DGLA, dihomo $\gamma$-linolenate; tLA trans-linoleate; CONT, control. 
PUFA at killing the tumour cells followed by EPA and cisLA and ALA. DHA was less effective whereas transLA and $\mathrm{C}_{18: 0}$ were not lethal. Similarly, the growth of tumour cells was more inhibited than the growth of normal cells in the presence of some PUFA, but not others (Bégin et al. 1986).

Selectivity of the anti-tumour effects of parental (LA and ALA) and 6-desaturated PUFA (other fatty acids tested) was confirmed by challenging tumour cells in the presence of non-tumour cells. As reported elsewhere (Bégin et al. 1986), in these tests. GLA, AA, EPA, DGLA and DHA but not LA and ALA eliminated tumour cells effectively. GLA and DGLA were the cytotoxic PUFA showing the greatest selectivity. This difference in the sensitivity observed between tumour and non-tumour cell lines of different tissue origins was fully reproduced between a tumour cell line and its corresponding normal cell type (Bćgin et al. 1989). Cancer cell sensitivity to the various PUFA do vary, but to date, after investigating over twenty different human cancer cell lines, no cancer cell line investigated has yet been found which cannot be killed by at least one PUFA, and most cell lines are susceptible to the lethal effects of several different PUFA (Leary et al. 1984; Bégin, 1987).

As yet there are only a limited number of studies on the use of 6-desaturated PUFA in vivo. In various animal tumour models, evening primrose (Oenothera biennis) oil (EPO) enriched in LA and GLA, and fish oil enriched in EPA and DHA blocked tumour development when added in the diet (Ghayur \& Horrobin, 1981; Karmali et al. 1984, 1985; Jurkowski \& Cave, 1985; Gabor \& Abraham, 1986; Abou El-Ela et al. 1987; Pritchard et al. 1990). Other studies using EPO have shown no effects (Ramchurren et al. 1985; Lee \& Sugano, 1986). There have been no epidemiological studies attempting directly to look at the relationships between the 6-desaturated fatty acids and human cancer.

Ionizing radiation is capable of generating free radicals which lead to lipid peroxidation. Both free radicals and PUFA peroxidation products can damage DNA and one of the late effects of radiation is the development of cancer. It, therefore, seems reasonable to consider that the greater the PUFA levels the greater the genetic damage. Contrary to expectation, injection of LA at physiological concentrations after irradiation protected chromosomes in mouse bone-marrow cells in vivo and human lymphocytes in vitro from damage induced by gamma radiation (Norman et al. 1988). Metabolites of LA such as GLA, prostaglandins PGE1 and PGI2 were also protective in mouse bone marrow when added after irradiation (Das et al. 1985).

\section{MECHANISM OF PUFA-INDUCED ANTI-TUMOUR TOXICITY}

Four sets of experiments suggested that lipid peroxidation was playing a key role in PUFA-induced cytotoxicity. First, the levels of hydroperoxide degradation products and of superoxide radicals were compared in PUFA-supplemented human breast cancer cells and human normal skin fibroblasts or normal simian kidney cells used as a working model. As shown in Fig. 2, PUFA which were most effective in destroying the tumour cells were those which produced the highest levels of superoxide radicals and hydroperoxides degradation products measured as thiobarbituric acid-reactive material (TBARM) (Gavino et al. 1981). Higher concentrations of these toxic products were found in the cancer cells than in the non-tumour cells. Second, using GLA-supplemented human breast cancer cells in conditions described in Bégin et al. (1988), superoxide 
Tumour

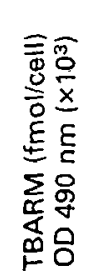

Non-tumour

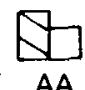

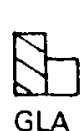

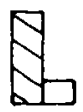

EPA DHA
Tumour:non-tumour

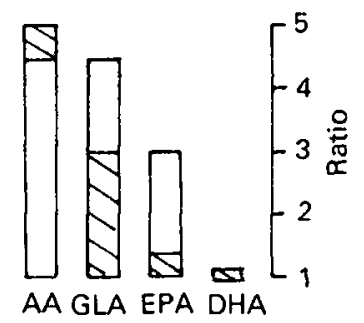

Fig. 2. Levels of superoxide radicals and hydroperoxides degradation products in tumour and non-tumour cells supplemented with polyunsaturated fatty acids (PUFA). Cells in parallel cultures were grown in the presence of $20 \mu \mathrm{g}$ indicated fatty acid/ml. Superoxide radicals $(\Gamma)$ were measured in human breast tumour cells (ZR-75-1) and normal human skin fibroblasts (CCD-41SK) by nitroblue tetrazolium reduction $3 d$ after supplementation (before the appearance of cytopathological effects). Values are expressed as optical density (OD) at $490 \mathrm{~nm}$. Hydroperoxides degradation products ( $\square$ ) were measured in human breast tumour cclls and normal simian kidney cells (CV-1) as thiobarbituric acid-reactive material (TBARM). Values are expressed as malonaldehyde-equivalent (fmol/cell) on day 6 after supplementation (at which time arachidonate (AA) had killed all tumour cells). The effects of other fatty acids in parallel cultures on these variables were also determined at that time for comparison. GLA, $\gamma$-linolenate; EPA, eicosapentaenoate; DHA, docosohexaenoate: CONT, control.

dismutase ( $E C$ 1.15.1.1), an enzyme known to block the production of superoxide radicals and antioxidants like $\alpha$-tocopherol, butylated hydroxytoluene and butylated hydroxyanisole known to block the propagation of lipid peroxidation inhibited the cytotoxic effects dose dependently. The removal of hydroperoxides by the addition of glutathione peroxidase ( $E C$ 1.11.1.9) or selenium also inhibited the cytotoxic effects dose dependently. In contrast, iron known to catalyse the degradation of hydroperoxides enhanced the killing of cancer cells by GLA. Third, using inhibitors of eicosanoid synthesis, we confirmed that neither inhibitors of cyclooxygenase or of lipoxygenase ( $E C$ 1.13.11.12) nor both inhibited the effect of GLA. Fourth, the addition of $\alpha$-tocopherol to the cancer cell cultures challenged with EPA reduced both cell killing and hydroperoxide degradation products (Bégin et al. 1988).

The differences found in TBARM in the cancer cells supplemented with GLA, AA, EPA and DHA may reflect differences in the rate of lipid peroxidation and in the rate of metabolism of TBARM or differences in the uptake or distribution of the PUFA. The most unexpected result was the relative ineffectiveness of DHA in either raising TBARM levels or killing the cancer cells in spite of its high degree of unsaturation and its expected readiness to peroxidize. Results of incorporation studies demonstrated that tumour cells incorporated equal or less amounts of PUFA than non-tumour cells (Das et al. 1987). However, differences in the proportion of the added PUFA into phospholipids and ether lipids were observed depending on the PUFA and between tumour and non-tumour cell lines (Das et al, 1987). Although preliminary, since the PUFA levels incorporated into phospholipids and neutral ether lipids varicd concomitantly but in opposite directions, the results suggest that the greater the proportion of the PUFA into phospholipids compared to the proportion in the neutral ether lipids the greatcr the cytotoxic potential of the PUFA. 
In the light of the anti-tumour activity of LA-derived 6-desaturated PUFA, the interpretation linking the tumour-promoting effect of LA (as observed in rodents) to increased peroxidation must be re-examined. Hypotheses as to how dietary fatty acid composition decreases tumour growth include (1) changes in fatty acid composition of the membranes, (2) alterations in the physical-chemical characteristics of the membranes, (3) changes in prostaglandin metabolism, (4) modulation of intracellular hormone action. The ability of PUFA to modify invasiveness and the host defence system is another important mechanism by which they exert their anti-tumour effects in the host (Bégin, 1987).

\section{DESIRABLE EFFECTS OF PUFA SUPPLEMENTATION IN DISEASES}

EPO and borage (Borago officinalis) seed (BO) oils, rich in LA and GLA, and fish oil, rich in EPA and DHA, have been used as dietary supplements either singly or in combination in attempts to prevent or to treat inflammatory-immunopathological responses with encouraging results (Kunkel et al. 1981; Stackpoole \& Mertin, 1982; Prickett et al. 1983; Kremer et al. 1987; Papanicolaou, 1987; Belch et al. 1988; Tate et al. 1988). These studies suggest that certain PUFA can prevent and suppress the development of acute and chronic inflammation that can lead to tissue damage. One application of these findings is making its way in the treatment of rheumatoid arthritis: it was proved possible for $80-90 \%$ of the patients with mild rheumatoid arthritis to decrease or stop non-steroidal anti-inflammatory drug treatment when $6 \mathrm{~g}$ EPO or EPO-fish oil was given (Belch et al. 1988). This was achieved with no deterioration in clinical or laboratory measures of rheumatoid arthritis activity. Fish oil and olive oil, the latter at three times the dose used for EPO or EPO-fish oil, appeared also effective in improving rheumatoid patients (Gail Darlington, 1987; Kremer et al. 1987).

In alcohol-dependent patients, chronic ethanol consumption decreases cell membrane fluidity and leads to a decrease in LA levels as well as an alteration in the LA:AA ratio due to the ability of ethanol to inhibit the enzymes associated with the conversion of LA to AA (Glen et al. 1987). Consumption of either $n-3$ or $n-6$ PUFA in the form of saffiower oil, EPO, or cod liver oil, all sharply reduced ethanol consumption in hamsters (Cunnane, 1985) and both GLA and AA protected against ethanol-induced damage in rats (Horrobin, 1987). In humans, results of clinical trials on the effects of fatty acid supplements during alcohol withdrawal have been so far limited to fatty acid supplements of the $n-6$ series. For example, in a double-blind, placebo-controlled trial, EPO reduced the requirement for tranquillizers and produced a significantly faster return of liver enzymes toward normal than placebo (Glen et al. 1987).

\section{CONCLUSION}

The results of these studies argue against the idea that PUFA supplementation makes worse the diseases in which free radicals have been implicated. PUFA supplementation resulted in an elevation of the concentrations of PUFA in the tissue examined. At the same time that there is an elevation in the concentrations of substrates for lipid peroxidation, there is either no change in the disease state or a significant improvement. Only in rare cases has PUFA administration been shown to make a disease worse. 
Free radicals could cause damage either by destroying necessary PUFA or by reacting with valuable PUFA to form toxic peroxidation products and other substances which actually do the damage or both. The results yet available suggest that the loss of PUFA due to free radical attack is important. PUFA supplementation may be helpful rather than harmful possibly due in part to the quenching of free radicals by the presence of the PUFA and in part to replacement of PUFA damaged by peroxidation.

These observations indicate that, with regard to many diseases, possibly including cancer, PUFA supplementation with avoidance of $\mathrm{AA}$ is not harmful and may be protective or even therapeutic.

\section{REFERENCES}

Abou El-Ela, S. H., Prasse, K. W. \& Carroll, R. (1987). Effects of dietary primrosc oil on mammary tumorigenesis induced by 7,12-dimcthylbenz(a) anthracene. Lipids 22, 1041-1044.

Bégin. M. E. (1987). Effects of polyunsaturated fatty acids and of their oxidation products on cell survival. Chemistry and Physics of Lipids 45, 269-313.

Bégin, M. E., Ells. G., Das. U. N. \& Horrobin, D. F. (1986). Differential killing of human carcinoma cells supplemented with $n-3$ and $n-6$ polyunsaturated fatty acids. Journal of the National Cancer Institute 77, $1052-1062$.

Bégin, M. E., Ells, G. \& Horrobin, D. F. (1988). Polyunsaturated fatty acid-induced cytotoxicity against tumor cells and its relationship to lipid peroxidation. Journal of the National Cancer Institute 80, 188-194.

Bégin, M. E., Sircar, S. \& Weber, J. M. (1989). Differential sensitivity of tumorigenic and genetically related non-tumorigenic cells to cytotoxic polyunsaturated fatty acids. Anticancer Research 9, 1049-1052.

Belch, J. F., Ansell, D., Madho, K. R., O'Dowd, A. \& Sturrock, R. D. (1988). Effects of altering dictary essential fatty acids on requirements for non-steroidal anti-inflammatory drugs in patients with rheumatoid arthritis: a double blind placcbo controlled study. Annals of Rheumatic Diseases 47, 96-104.

Cheeseman, K. H., Burton, G. W., Ingold, K. U. \& Slater, T. F. (1984). Lipid peroxidation and lipid antioxidants in normal and tumor cells. Toxicology and Pathology 12, 235-239.

Cheeseman. K. H., Collins, M., Proudfoot, K. \& Slater, T. F. (1986). Studies on lipid peroxidation in normal and tumor tissues. The Novikott rat liver tumor. Biochemical Joumal 235, 507-514.

Cunnane, S. C. (1985). Essential fatty acids decrease ethanol preference in the hamster: possible relation to increased liver cholesterol. In 2nd International Congress on Essential Fatty Acids, Prostaglandins and Leukotrienes, London, Abstr. 22 [M. Crawford, editor]. London: Zoological Society of London.

Das, U. N., Huang, Y. S.. Bégin, M. E., Ells, G. \& Horrobin, D. F. (1987). Uptake and distribution of cis-unsaturated fatty acids and their effect on free radical generation in normal and tumor cells in vitro. Free Radical Biology and Medicine 3, 9-14.

Das, U. N.. Ramadevi, G., Rao, K. P. \& Rao, M. S. (1985). Prostaglandins and their precursors can modify genetic damage induced by gamma-radiation and benzo(a)pyrene. Prostaglandins 29, 911-920.

Gabor, H. \& Abraham, S. (1986). Effect of dictary menhaden oil on tumor cell loss and the accumulation of mass of a transplantable mammary adenocarcinoma in BALB/c mice. Journal of the National Cancer Institute 76, 1223-1229.

Gail Darlington, L. (1987). Olive oil for rheumatoid patients? British Journal of Dermatology 26, Suppl. 2, 129.

Gavino, V. C., Miller, J. S., Ikharebha, S. O., Milo, G. E. \& Cornwell, D. G. (1981). Effects of polyunsaturated fatty acids and antioxidants on lipid peroxidation in tissue cultures. Journal of Lipid Research 22, 763-769.

Ghayur, T. \& Horrohin, D. F. (1981). Effects of essential fatty acids in the form of evening primrose oil on the growth of the rat R3230AC mammary adenocarcinoma. IRCS Journal of Medical Science 9, 582.

Glen, I., Skinner, F., Glen, E. \& MacDonell, L. (1987). The role of essential fatty acids in alcohol dependence and tissuc damage. Alcoholism: Clinical and Experimental Research 11, 37-41.

Horrobin, D. F. (1987). Essential fatty acids, prostaglandins, and alcoholism: an overview. Alcoholism: Clinical and Experimental Research 11.2-9.

Horrobin, D. F. \& Bégin, M. E. (1989). Essential fatty acid: metabolism, interaction with free radicals, and clinical use. In Handbook of Free Radicals and Antioxidants in Biomedicine. vol. II, pp. 17-27 [J. Miguel, editor]. Boca Raton: CRC Press. 
Jurkowski, J. J. \& Cave, W. T. Jr (1985). Dietary effects of menhaden oil on the growth and membrane lipid composition of rat mammary tumors. Journal of the National Cancer Institute 74, 1145-1150.

Karmali, R. A.. Marsh, J. \& Fuchs. C. (1984). Effect of omega-3 fatty acids on growth of a rat mammary tumor. Journal of the National Cancer Institute 73, 457-461.

Karmali, R. A.. Marsh, J. \& Fuchs, C. (1985). Effects of dictary enrichment with gamma-linolenic acid upon growth of the R3230AC mammary adenocarcinoma. Joumal of Nutrition and Growth Cancer 2, 41-51.

Kremer, J. M., Jubiz, W., Michalek, A., Rynes, R., Bartholomew, L., Bigaouette, J., Timchalk, M., Beeler, D. \& Liniger, L. (1987). Fish oil fatty acid supplementation in active rheumatoid arthritis. Annals of Internal Medicine 106, 496-503.

Kunkel, S. L., Ogawa, H., Ward, P. A. \& Zurier, R. B. (1981). Suppression of chronic inflammation by evening primrose oil. Progress in Lipid Research 20, 885-887.

Lcary, W. P., Robinson, K. M., Booyens, J. \& Dippenaar, D. (1984). Some effects of gamma-linolenic acid on cultured human oesophageal carcinoma cells. South African Medical Journal 62, 681-688.

Lee, J. H. \& Sugano, M. (1986). Effects of linoleic and gamma-linolenic acid on 7,12-dimethylbenz(a)anthracene-induced rat mammary tumors. Nutrition Reports International 34, 1041-1049.

Masotti, L., Casali, E. \& Galeotti, T. (1988). Lipid peroxidation in tumour cells. Free Radical Biology and Medicine 4, 377-386.

Norman, A., McBride, W. H., Bennett, L. R., Santos Mello, R., Iwamoto, K. \& Hidmi, H. (1988). Postirradiation protection of chromosomes by linolenate. International Journal of Radiation Biology 54, 521-524.

Papanicolaou, N. (1987). Alteration of mercuric-chloride-induced autoimmune glomerulonephritis in BrownNorway rats by herring oil, evening primrose oil and OKY -046, a selective TXA-synthetase inhibitor. Prostaglaindins, Leukotrienes and Medicine 27, 129-149.

Prickett, J. D., Robinson, D. R. \& Steinberg, A. D. (1983). Effects of dietary enrichment with eicosapentaenoic acid upon autoimmune nephritis in female NZB/NZW/F1 mice. Arthritis and Rheumatism 26, 133-139.

Pritchard, G. A. \& Mansell. R. E. (1990). The effects of essential fatty acids on the growth of breast cancer and melanoma. In Omega-6 Essential Fatty Acids: Pathophysiology and Roles in Clinical Medicine, pp. 377-390 [D. F. Horrobin, editor]. New York: Alan R. Liss, Inc.

Ramchurren, N., Botha, J. H. \& Leary, W. P. (1985). An investigation into the effects of gamma-linolenic acid on murine sarcoma M52 B. South African Journal of Science 81, 331.

Roos, D. S. \& Choppin, P. W. (1984). Tumorigenicity of cell lines with altercd lipid composition. Proceedings of National Academy of Sciences, USA 81. 7622-7626.

Roos, D. S. \& Choppin, P. W. (1985). Biochemical studies on cell fusion. 1. Lipid composition of fusion-resistant cells. Journal of Cell Biology 101, 1578-1590.

Stackpoole, A. \& Mertin, J. (1982). The effect of prostaglandin precursors in in vivo models of cell-mediated immunity. Progress in Lipid Research 20, 649-654.

Tate, G. A., Mandell, B. F., Karmal, R. A., Baker, D. G., Schumacher, H. R. Jr. \& Zurier, R. B. (1988). Suppression of monosodium urate crystal induced acute inflammation by diets enriched with gammalinolenic and eicosapentaenoic acids. Arthritis and Rheumatism 31, 1543-1551. 